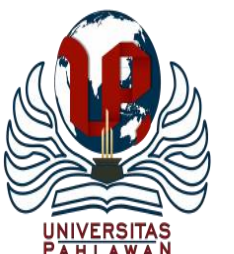

Edukatif : Jurnal Ilmu Pendidikan Volume 2 Nomor 2 Tahun 2020 Halm 176- 180

EDUKATIF: JURNAL ILMU PENDIDIKAN

Research \& Learning in Education

https://edukatif.org/index.php/edukatif/index

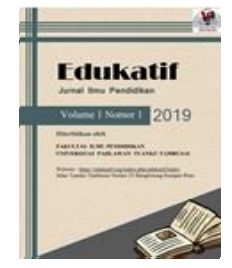

\title{
Analisis Kebijakan terkait Kebijakan Literasi Digital di Sekolah Dasar
}

\author{
Ida Safitri ${ }^{1}$, Sufyarma Marsidin ${ }^{2}$, Ahmad Subandi $^{3}$ \\ Universitas Negeri Padang, Sumatera Barat, Indonesia ${ }^{1,2,3}$ \\ E-mail : isafitri24@gmail.com ${ }^{1}$ sufyarma1954@gmail.com ${ }^{2}$ subandi@fip.unp.ac.id ${ }^{3}$
}

\begin{abstract}
Abstrak
Artikel ini menganalisis kebijakan literasi digital sekolah dasar.Berdasarkan penelitian melalui kajian pustaka, Gerakan literasi sekolah merupakan sebuah gerakan dalam upaya menumbuhkan budi pekerti yang sesuai dengan Permendikbud Nomor 23 Tahun 2015 yang bertujuan agar siswa memiliki budaya membaca dan menulis sehingga terciptanya pembelajaran sepanjang hayat. Literasi digital merupakan kompetensi seorang dalam menggunakan media digital dalam menemukan, memanfaatkan, mengolah, mengemas, mengevaluasi dan menyebar luaskan informasi secara benar, bijak dan bertanggung jawab.
\end{abstract}

Kata kunci: kebijakan, literasi digital, sekolah dasar

\section{Abstract}

This article analyzes the digital literacy policy of elementary schools. Based on research through literature review, the school literacy movement is a movement in an effort to foster character that is in accordance with Permendikbud No. 23 of 2015 which aims to make students have a culture of reading and writing so as to create lifelong learning. Digital literacy is a person's competence in using digital media in finding, utilizing, processing, packaging, evaluating and disseminating information correctly, wisely and responsibly.

Keywords: policy, digital literacy, primary school

Copyright (c) 2020 Ida Safitri, Sufyarma Marsidin, Ahmad Subandi

$\triangle$ Corresponding author:

Address :

Email : isafitri24@gmail.com

Phone :

DOI: 10.31004/edukatif.v2i2.123
ISSN 2656-8071 (Media Cetak)

ISSN 2656-8063 (Media Online) 


\section{PENDAHULUAN}

Gerakan literasi sekolah merupakan sebuah gerakan dalam upaya menumbuhkan budi pekerti yang sesuai dengan Permendikbud Nomor 23 Tahun 2015 yang bertujuan agar siswa memiliki budaya membaca dan menulis sehingga terciptanya pembelajaran sepanjang hayat.

Indonesia dikatakan darurat membaca, yang akan mengkhawatirkan masa depan bangsa. Dengan gerakan literasi, sekolah diharapkan dapat memfasilitasi secara optimal melalui pengadaptasian program kegitan wajib: (1) menerapkan program 15 menit membaca buku selain buku pelajaran sebelum pembelajaran dimulai, (2) melakukan kegiatan olah fisik seperti SKJ yang dilakukan secara berkala dan rutin minimal seminggu sekali oleh seluruh warga sekolah (guru, tenaga kependidikan, siswa).

Keterlibatan ekosistem pendidikan sangat diperlukan sejak penyusunan konsep, kebijakan, penyediaan materi pendukung, sampai pada kampanye literasi agar kebijakan yang digadang oleh pemerintah dilaksanakan sesuai harapan dan kebutuhan masyarakat.

Gerakan Literasi Nasional diharapkan menjadi pendukung keluarga, sekolah, dan masyarakat mulai dari perkotaan sampai ke wilayah terjauh untuk berperan aktif dalam menumbuhkan budaya literasi.

Upaya untuk meningkatkan gerakan literasi digital sudah digadang-gadang oleh pemerintah dari lama, berbagai macam pendekatan sudah dialukan oleh pemerintah. Berdasarkan survei (APJII, 2017) terdapat kesenjangan dalam penggunaan internet, penyalahgunaan internet, meluasnya hoax, itu semua adalah faktor rendahnya literasi digital di Indonesia.

\section{METODE PENELITIAN}

Metode penelitian yang dipakai adalah studi perpustakaan (library research). Studi kepustakaan yaitu studi yang digunakan dalam pengumpulaan data dari berbagai sumber bacaan, buku, jurnal, maupun artikel.

\section{HASIL DAN PEMBAHASAN PENELITIAN \\ Pengertian Literasi Digital}

Istilah literasi digital dipopulerkan oleh (Gilster \& Watson, 1997), Gilster berpandangan bahwa setiap orang harus membekali dirinya dengan kecakapan dalam pengunaan dan pemahaman informasi yang didapat dari berbagai sumber digital. Ia juga menyampaikan bahwa literasi digital merupakan keterampilan menggunakan piranti digital dalam kehidupan sehari-hari. Sedangkan UNESCO dalam (Maulana, 2015) memandang literasi digital sebagai kecakapan hidup modern yang perlu dikuasai.

Douglas A.J. Belshaw dalam (Santoso et al., 2018) mengatakan bahwa dalam mengembangkan literasi digital terdapat delapan elemen esensial, yaitu sebagai berikut: kultural, kognitif, kontruktif, komunnikatif, keperccayan diri, kreatif, kritis, dan bertanggung jawab secara sosial

Literasi digital mencangkup pemahaman seseorang tentang konten digital. Seseorang seharusnya sadar bahwa setiap konten yang terdapat di internet tidak sama kualitas kontennya. Sangat tidak mungkin jika semua konten yang ada di internet, (Sulistyo-Basuki, 2013) dengan 
178 Analisis Kebijakan terkait Kebijakan Literasi Digital di Sekolah Dasar - Ida Safitri, Sufyarma Marsidin, Ahmad Subandi

DOI: 10.31004/edukatif.v2i2.123

semakin seringnya seseorang mengakses internet, lambat laun dia akan mulai paham mana saja portal digital yang memiliki kualitas informasi yang baik dan mana saja portal digital yang kualitas informasi rendah bahkan palsu (hoax).

Dari beberapa pandangan diatas, literasi digital tidak hanya mencangkup kemampuan teknis seseorang dalam menggunakan alat (tools) atau piranti ICT, namun juga mencangkup pengetahuan dan keterampilan seseorang dalam memahami suatu konten sehingga pada akhirnya goals-nya adalah mampu menciptakan pengetahuan baru. Dengan demikian dapat diambil kesimpulan bahwa literasi digital merupakan kompetensi seorang dalam menggunakan media digital dalam menemukan, memanfaatkan, mengolah, mengemas, mengevaluasi dan menyebar luaskan informasi secara benar, bijak dan bertanggung jawab.

\section{Prinsisp Pengembangan Literasi Digital}

Konsep literasi digital sebetulnya tidak terlepas dari dua sudut pandang. Pertama, literasi komputer, merupakan kemampuan teknis seseorang dalam menggunakan perangkat komputer. Sedangkan yang kedua, literasi informasi, merupakan kemampuan seseorang dalam menemukan, menggunakan, mengemas, mengevaluasi dan menyebarluas-kan informasi digital secara benar.

Menurut (Tim GLN Kemendikbud, 2017) bahwa ada 4 (empat) dasar prinsip pengembangan literasi digital, antara lain: pemahamaan, saling ketergantungan, faktor social, kurasi.
Dua aspek pendekatan yang dapat diterapkan dalam literasi digital yaitu pendekatan konsepttual dan operasionaal. Pendekatan konseptual berfokus pada aspek perkembangn kognitif dan sosial emosinal, sedangkan pendekatan operasional berfokus pada kemampuan teknis penggunaan media menurut (Tim GLN Kemendikbud, 2017).

Sedangkan Mayes dan Fowler, dalam (Tim GLN Kemendikbud, 2017) menyatakan bahwa dalam pengembanagn literasi digital melalui 3 tahapan, sebagai berikut:

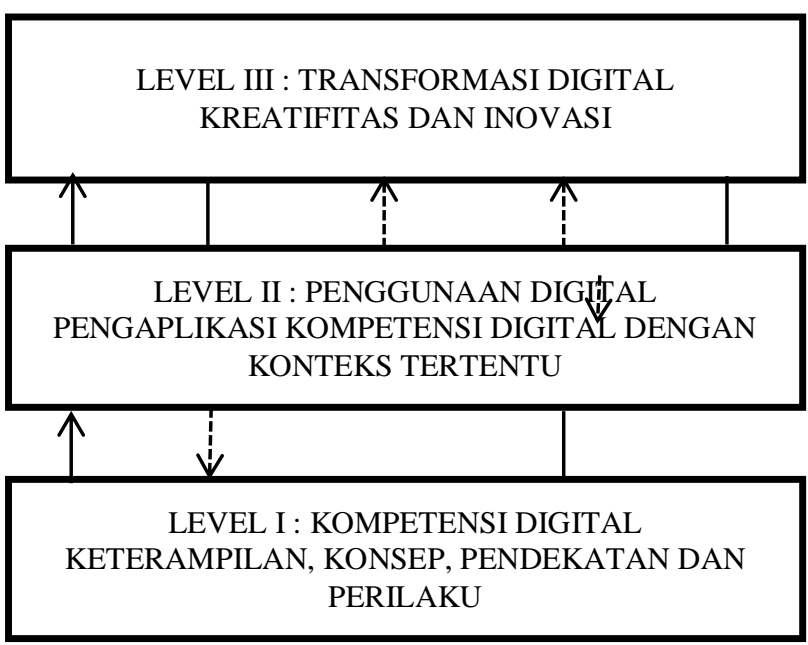

Prinsip pengemmbangan literasi digital, Menurut Mayes dan Fowler dalam (Tim GLN Kemendikbud, 2017)

Menurut Mayes dan Fowler (Tim GLN Kemendikbud, 2017) prinsip pengembangan literasi digital bersifat berjenjang. Pertama, komppetensi digital yang meliputi keterampiilan, pendekatan, konsep, dan perilaku. Kedua, penggunaan digital yang berujuk pada pengaplikasian kompetensi digital yang berhubungan dengan konteks tertentu. Ketiga, 
179 Analisis Kebijakan terkait Kebijakan Literasi Digital di Sekolah Dasar - Ida Safitri, Sufyarma Marsidin, Ahmad Subandi

DOI: 10.31004/edukatif.v2i2.123

transformasi digital yang membutuhkan kreatifitas dan inoovasi pada dunia digital.

\section{Konsep Literasi Digital di Lingkungan Sekolah}

Gerakan literasi sekolah diluncurkan oleh Kemdikbud pada tahun 2015. Peningkatan kualitas sumber daya manusia yang diharapakan dari Gerakan Literasi Sekolah. Gerakan ini diharapkan dapat mendorong meningkatkan semangat membaca bagi semua warga sekolah.

Derasnya informasi digital menuntut semua warga sekolah untuk cermat memilah dan memahami informasi yang di dapat. O'Brein \& Scharber dalam (Puspito, 2017) menyatakan bahwa literasi digital dapat digunakan sebagai sumber pembelajaran yang aktual yang dapat dijadikan acuan.

Dalam implementasi literasi digital di sekolah, diperlukan pengembangan program yang terintegrasi dengan kurikulum. Siswa perlu dilatih keterampilan literasi digitalnya, guru perlu dilatih agar meningkat kreatifitasnya dan pimpinan sekolah mendukung dan memfasilitasi gerakan literasi digital di sekolah. Menurut (Tim GLN Kemendikbud, 2017) ada 5 (lima) strategi yang dapat diterapkan dalam gerakan literasi digital di sekolah, sebagai berikut :

1. Penguatan kapasitas fasilitator

2. Peningkaatan juumlah dan raagam sumber belajar bermuutu

3. Perluasan akses sumber belajar bermutu dan cakupan peserta belajar

4. Peningkatan partisipasi publik

5. Penguatan tata kelola
Gerakan literasi digital identik dengan pola pikir kritis dan kreatif. Warga sekolah peka terhadap informasi yang berkembang, tidak mudah teermakan isu-isu yang tidak sehat, mampu memilih dan memilah informasi yang berkualitas, serta menjadi pribadi yang bijak dalam menggunakan media digital. Dengan demikian, jika gerakan literasi digital ini menjadi budaya di sekolah tertentu akan berdampak pada kehidupan kehidupan sosial dan budaya masyarakat, karena sekolah merupakan tempat strategis dalam membangun karakter. Membangun budaya literasi digital sangat memerlukan keterlibatan semua pihak. Sehingga keberhasilan capaian indikator bidang pendidikan dan kebudayaan melalui budaya literasi digital dalam menyonsong Revolusi Industri 4.0.

Implementasi program literasi digital yang diaharapkan dalam menyonsong Industri 4.0 menurut (National Education Association, 2010) yaitu critical thingker, communicator, collaborator dan creator.

\section{KESIMPULAN}

Literasi digital sangat diperlukan setiap individu dalam menghadapi perkembangan zaman. Gerakan literasi digital identik dengan pola pikir kritis dan kreatif. Warga sekolah peka terhadap informasi yang berkembang, tidak mudah teermakan isu-isu yang tidak sehat, mampu memilih dan memilah informasi yang berkualitas, serta menjadi pribadi yang bijak dalam menggunakan media digital. Dengan demikian, jika gerakan literasi digital ini menjadi budaya di sekolah tertentu akan berdampak pada kehidupan 
180 Analisis Kebijakan terkait Kebijakan Literasi Digital di Sekolah Dasar - Ida Safitri, Sufyarma Marsidin, Ahmad Subandi

DOI: 10.31004/edukatif.v2i2.123

kehidupan sosial dan budaya masyarakat, karena sekolah merupakan tempat strategis dalam membangun karakter. Membangun budaya literasi digital sangat memerlukan keterlibatan semua pihak. Keberhasilaan memmbangun liiterasi digital merupakan salah satu capaian indikator dalam dunia pendidikan.

\section{DAFTAR PUSTAKA}

APJII. (2017). Infografis Penetrasi \& Perilaku Pengguna Internet Indonesia. In Teknopreuner.

Gilster, P., \& Watson, T. (1997). An Excerpt from Digital Literacy. Digital Literacy.

Maulana, M. (2015). Definisi , Manfaat dan Elemen Penting Literasi Digital. Seorang Pustakawan Blogger.

National Education Association. (2010). Preparing 21st Century Students for a Global Society: An Educator's Guide to the "Four Cs." In Scientific Research An Academic Publisher.

Puspito, D. W. (2017). Implementasi Literasi Digital Dalam Gerakan Literasi Sekolah. Konferensi Bahasa Dan Sastra (International Conference on Language, Literature, and Teaching) II.

Santoso, R., Bernard, A., Chandrasekhar, U., Raghavender, N., Sharma, D., Çelik, A., ... Dutta, D. (2018). PENGARUH PROGRAM LITERASI SEKOLAH TERHADAP MINAT BACA PESERTA DIDIK DI SMA NEGERI 2 GADINGREJO TAHUN PELAJARAN 2017/2018. Journal of Materials Processing Technology. https://doi.org/10.1109/robot.1994.350900

Sulistyo-Basuki. (2013). Keilmuan Bidang Informasi dan Perpustakaan. SulistyoBasuki's Blog: Library and Information Science.

Tim GLN Kemendikbud. (2017). Literasi Digital. In Gerakan Literasi Nasional. 